\title{
Design and Implementation of a Push-Pull Inverter for Photovoltaic Portable Lamp
}

\author{
Nur Fairuz Mohamed Yusof ${ }^{1}$, Chanuri Charin ${ }^{2}$, Mazwin Mazlan ${ }^{3}$, Nurul Izni Rusli ${ }^{4}$, Abadal-Salam T. \\ Hussain $^{5}$, and Ahmad Mohamad Omar ${ }^{6}$
}

\begin{abstract}
This paper presents the prototype design of a push-pull topology inverter for photovoltaic (PV) portable lamp. The inverter is the main element that responsible in controlling the electricity flow between the PV module, battery and loads in any PV based system. A 10W solar PV module was used and the Direct Current (DC) electricity generated is stored in a $12 \mathrm{~V}$ rechargeable battery monitored by a charge controller circuit. Several Alternating Current (AC) lamps were used to show the load variations in this system. Circuit operation, simulation and design, along with experimental results taken from a laboratory prototype are presented. Based on prototype result analysis it has been possible for this inverter to feed others $\mathrm{AC}$ appliances during off- grid.
\end{abstract}

Keywords — Push-pull inverter, Photovoltaic, Portable lamp.

\section{INTRODUCTION}

$\coprod^{\mathrm{N}}$ $\mathrm{N}$ implementing a combination of renewable energy and power electronic device, there are few options to be considered in order to produce a properly operating solar inverter system. To satisfy the requirements for the consumers, the implementation of this system must deals with certain aspects of application. The system developed can be simple or complicated depend on the availability of electronic components, the output power desired from solar photovoltaic (PV) module and inverter, and the performance of the battery itself. A good working system indeed may produce a better performance which can be classified as a perfect system. Various of inverter topologies are studied throughout these years. The method of adding a chopper to conventional inverter topology is approached [2]. Apart from that, method using only two power switches to the topology and manipulating suitable switching signal in achieving alternating current (AC) outputs [4]. Latest approach is combinational of both push-pull and H-bridge topologies also being proposed [11].

This paper present an implementation of 4 power switches as a part of push-pull inverter topology with manipulating the centre tab transformer function to increase the $\mathrm{AC}$ voltage. Basically, a portable lamp being used to represent the AC

\footnotetext{
${ }^{1,3,4}$ School of Electrical System Engineering, Unimap, Perlis

${ }^{2,4}$ Faculty Technology Engineering, Unimap, Perlis

${ }^{6}$ Silterra Malaysia Sdn. Bhd, Kedah.
}

loads to show the best concept of implementing a cost effective solar system for AC appliances. The approach used is compatible with the current situation of instability of oil and coal prices with global warming phenomenon around the world [2]. This might affect the cost of generating electricity for the consumption in daily life. In fact, this project may become a new solution to overcome the problems that related to the increasing charges for electricity consumption due to the home appliances usage. Besides, this inverter concept also can be used in industrial applications such as variable speed drives for single-phase and three-phase AC motors, standby or emergency power supplies, induction heater and $\mathrm{AC}$ appliances run from an automobile battery [13]. The output of PV is in direct current (DC) form. Therefore, it requires sophisticated conversion techniques to make them usable because the power utilisation is mostly in $\mathrm{AC}$ form. This conversion can be done by using inverter that converts DC input into $\mathrm{AC}$ output [13]. The inverter is a critical component responsible for the control of electricity flow between the PV modules, battery and loads in any PV based system as shown in Figure 1.

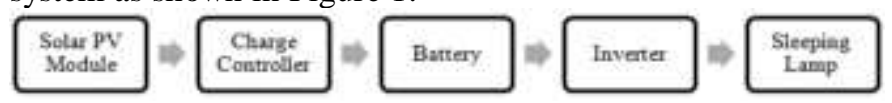

Fig.1: Block diagram representation of photovoltaic system.

\section{HARDWARE DESIGN}

\section{A. Inverter Design}

This prototype consists of four parts which operate in different level with different characteristics, but in the same phase to produce a good working system. The first part of the prototype is the input. This part consists of solar PV module which acts by delivering the power converted from the sunlight to the energy storage. Meanwhile, the energy storage part is covered by two components, which are charge controller and battery. The charge controller operates by keeping the battery properly charged by the solar PV module. As the battery is fully charged, the charge controller will cut off the current from the supply in order to prevent the battery from damaged. The third stage is the heart of the prototype which is single phase inverter. This part consists of the conversion process from DC voltage produced by the supply into $\mathrm{AC}$ voltage.

The inverter is connected in the flow between the battery and the load in order to transform the DC voltage from the 
battery into AC voltage. The $12 \mathrm{~V}$ output from the inverter is step up $230 \mathrm{~V}$ by using transformer as the load requires $230 \mathrm{~V}$ input for its normal operation. This prototype will utilize a $3 \mathrm{~W}$ light emitting diode (LED) light bulb as the AC load. This project implements the type of push-pull inverter application as the $\mathrm{DC}$ to $\mathrm{AC}$ converter. The circuit is designed by referring to the basic concept of push-pull topology circuit. The schematic diagram of the push-pull inverter is designed in Livewire software by using push-pull topology as shown in Figure 2.

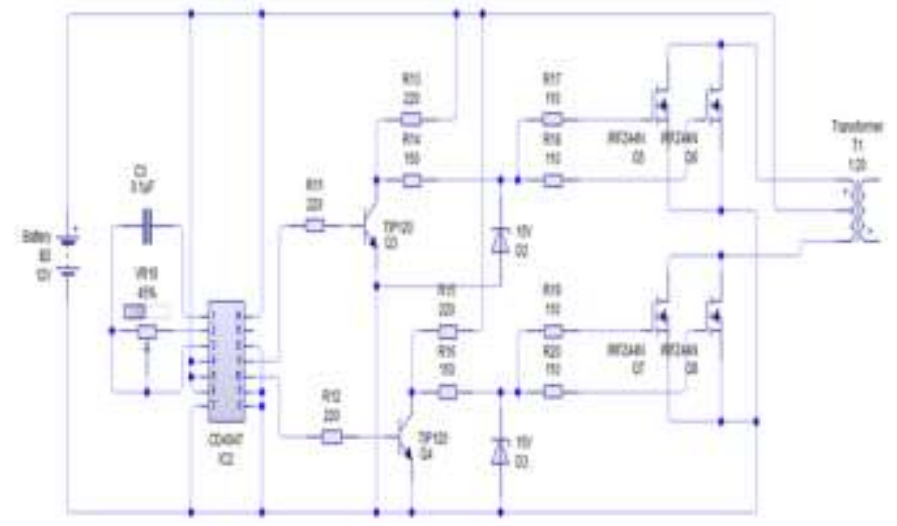

Fig. 2: Schematic diagram of push pull inverter with centre tab transformer

The push-pull topology is suitable for producing square and modified square wave inverter. The inverter switching circuit is built around a multi-vibrator component, CD4047 (IC2). This chip acts as the main component of the switching circuit. It produces three square wave signal outputs which are pin 10,11, and 13. Pin 13 of the IC2 produce the fundamental frequency waveform. Meanwhile, the output from pin 11 and 10 produces half the fundamental frequency. However, at pin 10 the signal is inverted to $180^{\circ}$ which indicates opposite characteristics to pin 11.

The frequency is determined by two components which are $0.1 \mu \mathrm{F}$ capacitor (C3) and $45 \mathrm{k} \Omega$ variable resistor (VR10) in order to obtain $50 \mathrm{~Hz}$ for the system. Other components such as NPN transistors, resistors, and zener diodes act as the gate driver for the Metal Oxide Semiconductor Field Effect Transistor (MOSFETs) to operate. As the base of TIP120 is grounded $(0 \mathrm{~V})$, it is switched OFF as no base current flows, hence no current flows from the emitter to the collector. This condition causing the MOSFET to switch OFF too, thus no voltage supplied from the battery via the center tapped transformer. If the base is in forward biased condition, TIP120 is switched ON as a current flow from the emitter to the collector. At this point, the MOSFET also switched ON. The gate switch, TIP120 conduct by turn based on the gating pulse received from the output pin multi-vibrator.

Meanwhile, the operations of the MOSFETs depend on the switching sequence of the TIP120. The designed circuit only involved two output pins of IC2 which are pins 10 and 11. Since the output signals from these two pins are inverted to each other by $180^{\circ}$, it changes the polarity of the center tapped transformer and producing a square wave output signal. The assembled push-pull inverter circuit must be connected to a center tapped transformer in order to operate. The selection of the correct size of the transformer is important to obtain the desired output voltage. Since the load used in the project consumed a very low current from the battery, the maximum rated current of the transformer can be very low. Hence, a center tapped transformer rated at $2 \mathrm{~A}$ with ratio 1: 20 was selected. It is suitable for the designed inverter circuit since the load carry a very low current from the supply. If the current flow exceeds the maximum rated current of the transformer, the circuit may not operate as the component in the circuit could be damaged. The complete prototype is shown in Figure 4.

\section{B. PV Controller Design}

The circuit is built around a 555 timer IC (IC1) as shown in Figure 3. This chip has two inputs which are pin 2 and pin 6. These input voltages are compared to a set of reference voltages that are based on the input voltage. A 7805 voltage regulator (RG1) is used to fix the input voltage to $5 \mathrm{~V}$. Each of the input pin is connected to a $10 \mathrm{k} \Omega$ multi-turn potentiometer (VR1 and VR2). These variable resistors act to adjust the reference voltage set at the two inputs. The output at pin 3 goes high in case of the voltage at pin 2 decreases below the reference voltage set. In other condition at pin 6 , as the input voltage increases above the reference voltage set at pin 6 , the pin 3 will become low.

Meanwhile, the type of relay used is Single Pole Double Throw (SPDT) rated at $12 \mathrm{~V}$ and $10 \mathrm{~A}$ (RL1). The common terminal of the relay is connected to the power supply which is the solar PV module whereas the normally close and normally open terminals are connected to the battery and dummy load respectively. In addition, two safety resistors of $330 \Omega$ (R8 and R9) are connected in the connection of push button at pin 6 and the connection of VR1 and VR2. The role of these two resistors is to protect the circuit against accidental short circuit in case of both push buttons (SW1 and SW2) are pressed concurrently or the push buttons are pressed when the potentiometers are at the limits of travel.

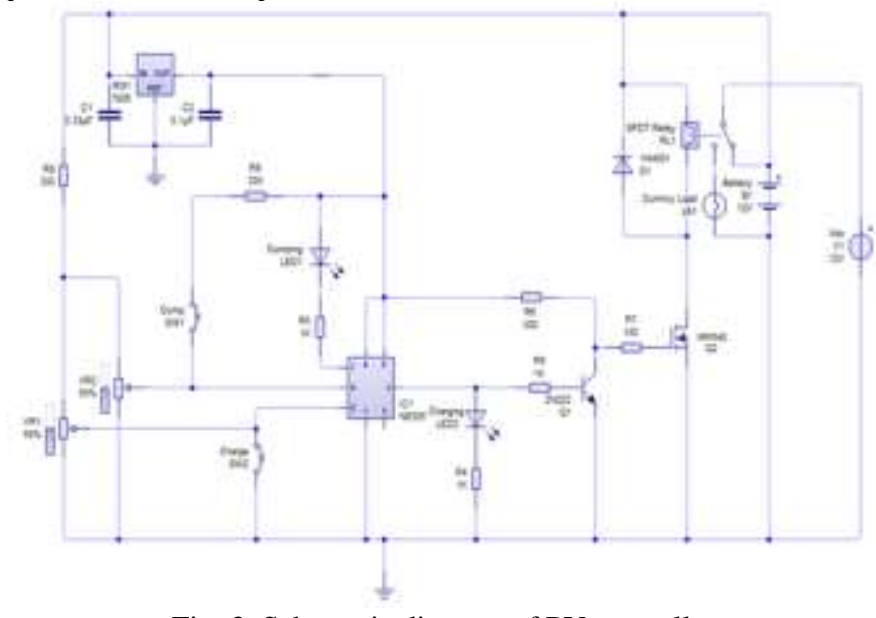

Fig. 3: Schematic diagram of PV controller 


\section{RESUltS AND DisCUSSION}

\section{A. Hardware setup}

If you are using Word, use either the Microsoft Equation Editor or the MathType add-on (http://www.mathtype.com) for equations in your paper (Insert | Object | Create New | Microsoft Equation or MathType Equation). "Float over text" should not be selected.

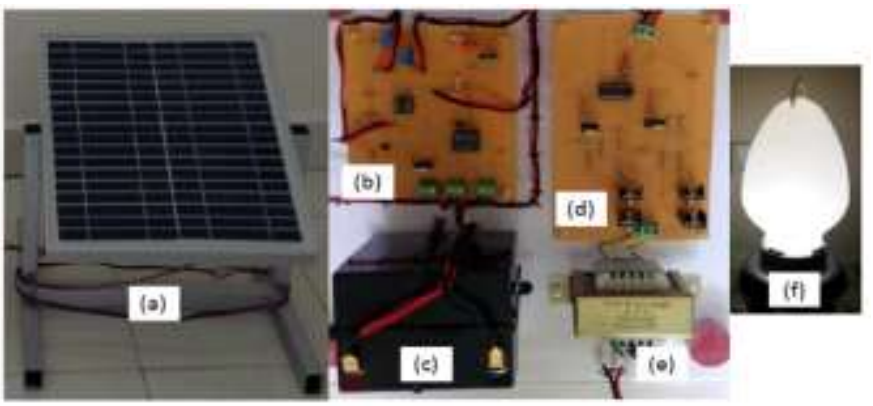

Fig 4: (a) Solar Panel (b) solar charger circuit (c) Battery (d) Push pull inverter (e) Centre tap transformer (f) AC load (3W LED lamp)

\section{B. Inverter Switching Signal at Oscilloscope}

As mentioned before, CD4047 IC acts as the switching component by implementing the function of multi-vibrator. Two output pins are used in generating the switching sequence which is pins 10 and 11 . The output produced from these pins is quite similar to the signal produced by the gating block in simulation. Pin 10 produce positive half-cycle signal while pin 11 signal is inverted to $180^{\circ}$ which indicates the negative half-cycle. The circuit was connected to the oscilloscope in order to get the display of output waveform. The waveform obtained from pins 10 and 11 is illustrated in Figure 5.

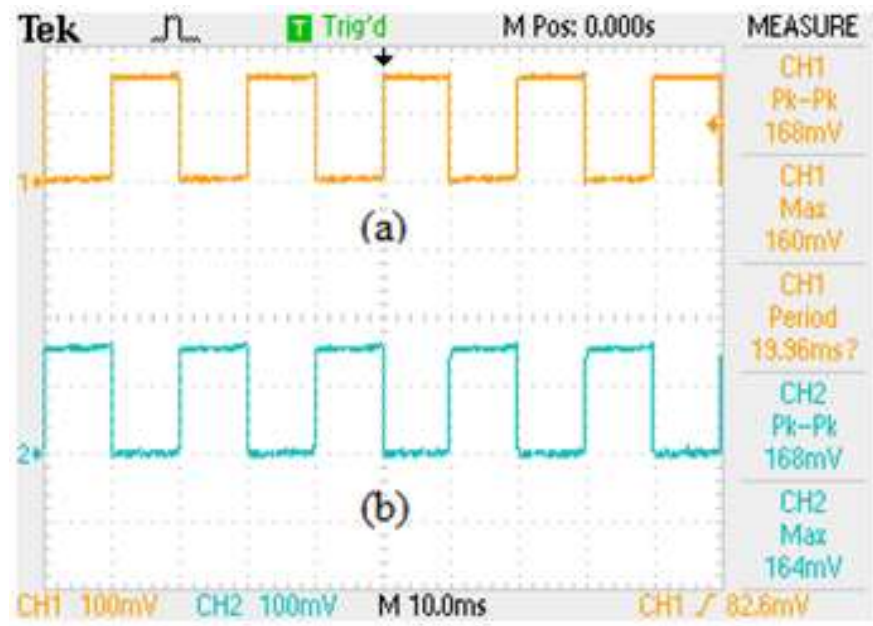

Fig. 5: (a) Output from pin 10 (b) Output from pin 11

The multi-vibrator IC produced a square wave pulse with a frequency of $50.06 \mathrm{~Hz}$ at both pins. As can be seen from Figure 4, when pin 10 is in high condition, the output waveform from pin 11 will be low. This situation indicates the output pins are inversely operated to each other. The pin 10 produced a square wave pulse with $168 \mathrm{mV}$ while pin 11 produced a square wave pulse with a $168 \mathrm{mV}$. The pulses will trigger the inverter MOSFETs power switches.

\section{Inverter Output at Oscilloscope}

The output waveform produced from the primary side of the transformer is displayed in Figure 6. The square wave signal has been amplified by the MOSFET at which the output waveform from (a) produced a $10.4 \mathrm{~V}$ peak to peak while (b) produced a $12.4 \mathrm{~V}$ peak-to-peak at $50.06 \mathrm{~Hz}$. This operation results the induced voltage at the secondary winding of the transformer. The output waveform at the secondary side of the transformer is shown (c) which indicated 254 VAC nearly to the expected value 230 VAC.

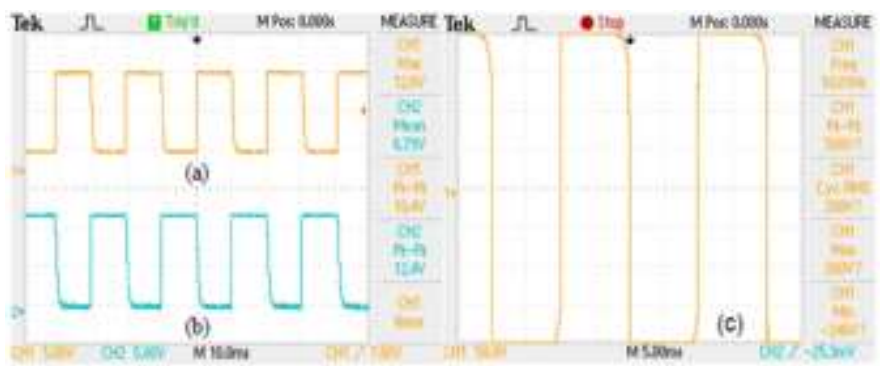

Fig. 6: (a) Output from pin 10 (b) Output from pin 11 at primary side of the transformer (c) Output voltage at the secondary side of the transformer

\section{D.Inverter Efficiency}

The efficiency of an inverter indicates how efficient the system works with the connection of the load at the output terminals. It describes the actual percentage of the input power from the battery that is converted and fed to the load. Equation (1) is used as a calculation measurement of several types of loads that have been connected to the push-pull inverter developed.

$$
\text { Efficiency, } \eta=\frac{\text { Output } \text { Power, }_{y} \text { Pout }}{\text { Input } \text { Power, } \text { Pin }_{\text {in }}} \times 100 \%
$$

As tabulate in Table I, the efficiency of the inverter with a $3 \mathrm{~W}$ LED lamp connected load is $66.23 \%$. At this rate, it can be classified that the efficiency of the inverter for a $3 \mathrm{~W}$ load is very low. Meanwhile, when testing with $18 \mathrm{~W}$ Compact fluorescent lamp (CFL) as the load the efficiency obtained is $92.61 \%$. However when the load rated at $21 \mathrm{~W}$ results in $96.83 \%$ efficiency which is the highest compared to the other two loads. The results produced by the variation of loads concluded that the efficiency of the inverter is low at $3 \mathrm{~W}$ load. As the load increased, the efficiency also increased. Thus, higher load connected to the inverter, higher the efficiency of the inverter.

TABLE I

THE INVERTER EFFICIENCY BASED ON LOADS VARIATION

\begin{tabular}{|c|c|c|c|c|c|c|c|}
\hline Load & $\begin{array}{c}\text { Input } \\
\text { Voltag } \\
e\end{array}$ & $\begin{array}{c}\text { Input } \\
\text { Current }\end{array}$ & $\begin{array}{c}\text { Output } \\
\text { Voltage } \\
\text { (Before } \\
\text { Transformer }\end{array}$ & $\begin{array}{c}\text { Output } \\
\text { Current } \\
\text { (Before } \\
\text { Transformer) }\end{array}$ & $\begin{array}{c}\text { Output } \\
\text { Voltage } \\
\text { (After } \\
\text { Transformer) }\end{array}$ & $\begin{array}{c}\text { Output } \\
\text { Current } \\
\text { (After } \\
\text { Transformer) }\end{array}$ & $\begin{array}{c}\text { Inverter } \\
\text { Efficiency }\end{array}$ \\
\hline $\begin{array}{c}\text { No } \\
\text { load }\end{array}$ & $\begin{array}{c}12.20 \\
\mathrm{~V}\end{array}$ & $0.254 \mathrm{~A}$ & $13.33 \mathrm{~V}$ & $0.213 \mathrm{~A}$ & $230.0 \mathrm{~V}$ & - & - \\
\hline $3 \mathrm{~W}$ & $\begin{array}{c}12.02 \\
\mathrm{~V}\end{array}$ & $0.795 \mathrm{~A}$ & $12.85 \mathrm{~V}$ & $0.486 \mathrm{~A}$ & $227.0 \mathrm{~V}$ & $27.88 \mathrm{~mA}$ & $66.23 \%$ \\
\hline $18 \mathrm{~W}$ & $\begin{array}{c}11.86 \\
\mathrm{~V}\end{array}$ & $1.385 \mathrm{~A}$ & $12.27 \mathrm{~V}$ & $0.768 \mathrm{~A}$ & $203.1 \mathrm{~V}$ & $74.90 \mathrm{~mA}$ & $92.61 \%$ \\
\hline $21 \mathrm{~W}$ & $\begin{array}{c}11.76 \\
\mathrm{~V}\end{array}$ & $1.758 \mathrm{~A}$ & $11.94 \mathrm{~V}$ & $0.815 \mathrm{~A}$ & $198.4 \mathrm{~V}$ & $100.90 \mathrm{~mA}$ & $96.83 \%$ \\
\hline
\end{tabular}

The complete hardware prototype of the $3 \mathrm{~W}$ portable AC lamp is tested. The lamp is switched on with nominal voltage 
of the battery was recorded. The voltage of the battery was measured in every single hour as the lamp operates until it suddenly lights off which indicates that the battery has been fully discharged. The test is conducted three times in order to identify the actual performance of the battery. Table II shows the voltage level of the battery measured every hour during the testing process. Based on the tabulated result can be conclude that the push- pull inverter can support maximum to 6 Hours operating.

TABLE II

PORTABLE INVERTER LAMP OPERATING TESTING

\begin{tabular}{|c|c|c|c|c|c|c|c|}
\hline \multirow{2}{*}{$\begin{array}{c}\text { Nominal } \\
\text { Voltage } \\
\text { (V) }\end{array}$} & \multicolumn{7}{|c|}{ Operating Hours } \\
\cline { 2 - 8 } & 1 & 2 & 3 & 4 & 5 & 6 & 7 \\
\cline { 2 - 8 } & \multicolumn{7}{|c|}{ Voltage of the Battery (V) } \\
\hline 12.41 & 12.13 & 11.90 & 11.59 & 11.06 & 9.11 & 2.57 & - \\
\hline 12.65 & 12.41 & 12.13 & 11.67 & 11.13 & 8.41 & 2.27 & - \\
\hline 12.69 & 12.45 & 12.17 & 11.56 & 11.12 & 7.98 & 3.05 & - \\
\hline
\end{tabular}

\section{CONCLUSION}

In this paper, a prototype of push-pull topology inverter was develops. The simulation was performed using the livewire software while the inverter hardware prototype consists of the PV module, charger controller circuit, battery, inverter circuit and step-up transformer. From the result obtained, the output waveform of this inverter circuit is square waveform. This inverter successfully converts the 12 VDC into nearly 230 VAC. The operation and performance of the inverter has also been confirmed by the prototype results of proposed converter. The results have been found in good agreement with the analysis presented in this paper. Therefore, this paper recommends the proposed topology to support other AC appliances rather than a portable lamp.

\section{ACKNOWLEDGMENT}

This research was supports by University Malaysia Perlis (UniMAP) Short Term Grant.

\section{REFERENCES}

[1] T. I Maris, St. Kourtesi, L. Ekonomou and G.P. Fotis, (November 2007), "Modeling of a Single-phase Photovoltaic Inverter", Elsevier Journal on Solar Energy Materials and Solar Cells, 91(18), pp. 1713-1725, Available : http://www.sciencedirect.com/science/article/pii/S0927024807002292

[2] A. K. Al-Mamun, N. Sundaraj, N. Ahmed, U. Ahamed, S.A.M. M. Rahman, R.B. Ahmad, and M. H. Kabir, "Design and Development of a Low Cost Solar Energy System for the Rural Area", presented at IEEE Conference on Systems, Process \& Control (ICSPC), 13-15 December, 2013. http://dx.doi.org/10.1109/SPC.2013.6735098

[3] J.P. Agrawal, Power electronic system: Theory and Design. America. Prentice Hall, 2011

[4] S.S. Shema, I. Daut, A.N. Syafawati, M. Irwanto and C. Shatri 2011. "Simulation of Push-Pull Inverter for Photovoltaic Application", presented at the 5th International Power Engineering and Optimization Conference (PEOCO), 6-7 June, 2011.

[5] S. G. Tesfahunegn, O. Ulleberg, T. M. Undeland, and P. J. S. Vie, “A Simplified Battery Charge Controller for Safety and Increased Utilization in Standalone PV Applications", presented at International Conference on Clean Electrical Power (ICCEP), 14-16 June, 2011. http://dx.doi.org/10.1109/ICCEP.2011.6036367
[6] O. Erdinc, N.G. Paterakis, J.P.S. Catalã, I.N. Pappi and A.G. Bakirtzi, "Smart Households and Home Energy Management Systems with Innovative Sizing of Distributed Generation and Storage for Customers", presented at 48th Hawaii International Conference on System Sciences (HICSS). 5-8 January, 2015. http://dx.doi.org/10.1109/hicss.2015.178

[7] S. Rohit and S.C. Bhattacharyya, (August 2013), "Off-grid electricity generation with renewable energy technologies in India: An application of HOMER", Elsevier Journal on Renewable Energy, 62, pp. 388-392, Available http://www.sciencedirect.com/science/article/pii/S0960148113003832

[8] M.M. Rahman, M.M Hasan, J.V. Paatero and R. R. Lahdelma, (February 2014), "Hybrid Application of Biogas And Solar Resources to Fulfill Household Energy Needs: A Potentially Viable Option In Rural Areas of Developing Countries". Elsevier Journal on Renewable Energy, 68, pp. 3545, Available http://www.sciencedirect.com/science/article/pii/S0960148114000597.

[9] O. Deveci, M. Onkol, H.O. Unver and Z. Ozturk, (May 2015), "Design and Development of a Low-Cost Solar Powered Drip Irrigation System Using Systems Modelling Language". Elsevier Journal of Cleaner Production, 102, pp. 529-544. Available: http://www.sciencedirect.com/science/article/pii/S0959652615004990

[10] Y. Iwafune, T. Ikegami, J.G.D.S. Fonseca, T. Oozeki, and K. Ogimoto, (March 2015), "Cooperative home energy management using batteries for a photovoltaic system considering the diversity of households". Energy Conversion and Management, 96, pp. 322-329. Available: http://www.sciencedirect.com/science/article/pii/S0196890415002046 http://dx.doi.org/10.1016/j.enconman.2015.02.083

[11] T.H. Lobaru and K.M. Salim, 2013. "Design And Implementation of A Micro-Inverter For Single PV Panel Based Solar Home System", presented at International conference on Informatics, electronics and vision (ICIEV). 17-18 May, 2013.

[12] J.W. Seo, S. Moon, J.H. Jang and J.H. Park, 2013. "Stand-Alone Operation with a Centralized Controller for Multiple PV Module Converters", presented at IEEE 10th International Conference on Power Electronics and Drive System (PEDS), 22-25 April, 2013.

[13] S. Nunir and Y.W. Li, "Residential Distribution System Harmonic Compensation Using PV Interfacing Inverter". IEEE Transactions on Smart Grid. vol. 2, pp. 816 - 827, March 2013.

[14] A. Tascikaraoglu, M. Uzunoglu, M. Tanrioven, and A.R. Boynuegri, "Smart Grid-Ready Concept of a Smart Home Prototype: A demonstration project in YTU", presented at 4th International Conference on Power Engineering, Energy and Electrical Drives (POWERENG), 13-17 May, 2013. http://dx.doi.org/10.1109/PowerEng.2013.6635850

[15] S. Anand, S.K. Gundlapalli and B.G. Fernandes, "Transformer-less Grid Feeding Current Source Inverter for Solar Photovoltaic System". IEEE Transactions on Industrial Electronics, vol. 61, pp. 5334-5344, May 2014. http://dx.doi.org/10.1109/TIE.2014.2300038 